\title{
Impact of Socioeconomic Status on Prevalence of Overweight and Obesity among Children and Adolescents in Urban India
}

\author{
Shabana Tharkar and Vijay Viswanathan \\ M.V. Hospital for Diabetes and Diabetes Research Centre, WHO Collaborating Centre for Research, Education and \\ Training in Diabetes, No-4, Main Road, Royapuram, Chennai-13, India
}

\begin{abstract}
To determine the prevalence and risk factors of overweight and obesity among the school children aged 8-15 years. A cross sectional design was adopted and 3 schools ( 2 private and 1 corporation schools) were selected by stratified cluster-sampling technique. Data was collected by interviewer administered method by trained research officers using a pre- tested and validated questionnaire to a total sample of 1193 school children from grades IV to X (i.e.) aged 8 to 15 years. Prevalence rates were calculated using WHO-BMI for age percentile chart 2007. Regression analysis was done to determine the risk factors associated with overweight. The overall prevalence of overweight was $12.1 \%$ among the children and $15.5 \%$ among the adolescents. Both overweight (22\%) and obesity $(13.7 \%)$ were highest among girls from affluent families. The mean anthropometric measurements, prevalence of overweight and obesity were higher among the urban affluent children. Factors associated with overweight were upper socioeconomic status (OR-3.4, CI-1.8 to 6.7, $\mathrm{P}<0.0001)$ and greater than 2 hours television watching (OR -2.5, CI- 1.1 to $5.4, \mathrm{P}<0.0001)$. The children had grossly inadequate knowledge about healthy lifestyle habits. Overweight and obesity are predisposing factors for many diseases. These findings suggest the need for early intervention programs, targeting the children from affluent society.
\end{abstract}

Keywords: Obesity, Overweight, Prevalence, School Children, Socioeconomic Status, Urban India.

\section{INTRODUCTION}

The $21^{\text {st }}$ century epidemiological transition is manifesting in the form of shift towards increase in prevalence of noncommunicable diseases (NCD's) and a decline in communicable diseases. There is established evidence that all NCD's are associated with overweight and obesity. Excess body fat is associated with insulin resistance, impaired glucose tolerance, hypertension, atherosclerotic risk factors and type 2 diabetes among children and adolescents [1-4]. Persistence of overweight and obesity into adulthood leads to cardiovascular disease risk, type 2 diabetes, hyperlipidemia, hyperinsulinemia, arthritis, sleep disorders and behavioral problems and cancer [5,6]. At a time when various public health policies were targeted and implemented to prevent malnutrition and stunted growth among the pediatric population of developing countries, today, overweight and obesity has also become a major public health concern especially in the urban areas [7, 8].

This study was done to assess the prevalence of overweight and obesity among the school children using the recently published WHO 2007 sex specific body mass index (BMI) for age percentile chart, which is considered to provide an appropriate reference curves for the world population aged $5-19$ years [9]. This study is the first of its kind in India to report the latest figures using these charts. There is virtually no data from India assessing knowledge and awareness levels of children about healthy lifestyle habits, hence it was also assessed simultaneously.

\footnotetext{
*Address correspondence to this author at the M.V. Hospital for Diabetes and Diabetes Research Centre, WHO Collaborating Centre for Research, Education and Training in Diabetes, No-4, Main Road, Royapuram, Chennai-13, India; Tel: +91-44-25954913; Fax: 91-44-2595 4919;

E-mail: dr_vijay@vsnl.com
}

\section{MATERIALS AND METHODOLOGY}

\section{Study Design and Subjects}

A cross sectional study was done on 1193 primary and secondary school children aged 8 to 15 years (IV grade to $\mathrm{X}$ grade) using stratified cluster sampling in Chennai. Generally, in India, children from low socioeconomic status (LSES) study in corporation schools which impart free education and children from upper socioeconomic status (USES) attend the private schools with fee structure of around 30,000 Indian rupees (INR)(750US\$) per annum. According to population probability sample 2 private schools and 1 corporation school were included in the study. Since the range of age distribution was wide, the study subjects were categorized into 2 groups - Children (8-12 years) and Adolescents (13-15 years). The study was limited to 8-15 years age, as children below 8 years were not cooperative and unable to respond to questions. The authorities did not grant permission to include students above 15 years.

The study protocol was approved by the ethics committee of the institution.

\section{Data Collection}

A well designed, pre-tested and validated questionnaire was administered to students of Grades IV to X after getting permission and written consent from the school principals. Data collection was carried out during September 2007 to February 2008. Anthropometric measurements were recorded and the survey instrument was interviewer administered by 2 well trained research officers.

\section{Survey Instrument Details}

The instrument contained 3 parts- a) Socio-demographic details b) anthropometric measurements c) questions on 
knowledge, attitude and practice related to obesity, diabetes, diet, physical activity and TV watching.

\section{Anthropometric Measurements and Definitions}

Anthropometric measurements taken in the study include weight in kilograms $(\mathrm{kg})$, height in centimeters $(\mathrm{cm})$ and waist circumference in centimeters $(\mathrm{cm})$. Height was measured with a standing stadiometer with a precision of $1 \mathrm{~mm}$ and weight was taken without shoes and recorded on a digital scale (Equinox, India) to the nearest 0.1 kilogram. Waist circumference was measured using a flexible tape placed mid way between the costal margin and iliac crest after expiration. BMI was calculated using the formula,

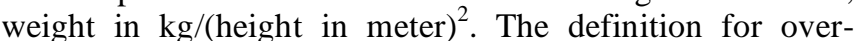
weight is $\mathrm{BMI} \geq 85^{\text {th }}$ percentile and obesity is $\mathrm{BMI} \geq 97^{\text {th }}$ percentile according to WHO 2007 sex specific BMI for age percentile charts.

\section{Knowledge Scores}

The percentage of respondents, who gave correct answers to questions regarding knowledge were assessed. Correct answers were awarded scores and total score was computed. The maximum attainable knowledge score was 8 . The scores obtained by the children were then compared across age, socioeconomic status and gender.

\section{Data Analysis}

Data were analyzed using the statistical software SPSS version 10.0. Prevalence rate for overweight and obesity was calculated based on the BMI values and cut off as defined above. Mean and standard deviation (SD) was calculated for anthropometric measurements. Test of significance for proportions was done by chi square test. A p value of $<0.05$ was taken as statistically significant. Multiple logistic regression analysis was done to determine the factors associated with overweight and obesity.

\section{RESULTS}

The overall prevalence of overweight $\left(\geq 85^{\text {th }}\right.$ percentile) was $12.1 \%$ among the children and $15.5 \%$ among the adolescents irrespective of SES and gender. Age and sexspecific prevalences of overweight and obesity are presented in Table 1. The prevalence of overweight and obesity was significantly higher among girls than boys $(\mathrm{P}<0.0001)$ and this was markedly seen in adolescence. There were highly significant differences in the prevalence of overweight and obesity between LSES and USES $(\mathrm{P}<0.05)$.

The anthropometric details of 1193 school children (boys: girls; 656: 537) is shown in Table 2. The students from USES had higher mean values of all growth parameters $(\mathrm{p}<0.0001)$ except adolescent males. The age wise distribution of mean values of BMI and waist circumference of the study subjects are shown in Figs. (1 and 2 ) respectively, which showed significant differences between $\operatorname{SES}\left(\chi^{2}=36.5 ; \mathrm{p}<0.0001\right)$.

Multiple logistic regression analysis showed that the factors associated with overweight are USES and watching TV for more than 2 hours daily. Children and adolescents from USES had 3.4 times higher odds of being overweight compared to those from LSES (confidence interval (C.I.): $1.8-6.7 ; \mathrm{p}<0.0001)$. Watching television for more than 2 hours daily increased the odds ratio (OR) of being overweight $(\mathrm{OR}=2.5)$ compared to children who watched television occasionally (C.I.: $1.1-5.4$; p<0.0001). Levels of physical activity did not appear as a significant factor in the regression analysis. However, re analysis of quartiles of physical activity with prevalence of overweight using chi square test showed significant independent association (children; $\chi^{2}=8.5, \mathrm{p}=0.04$ and adolescents; $\chi^{2}=13.6$, $\mathrm{p}=0.004)$.

Levels of knowledge about healthy lifestyle did not show significant association with overweight in this study but the children had poor awareness on healthy lifestyle habits. Mean knowledge scores attained by children are shown in

Table 1. Age and Gender Specific Prevalence of Overweight and Obesity

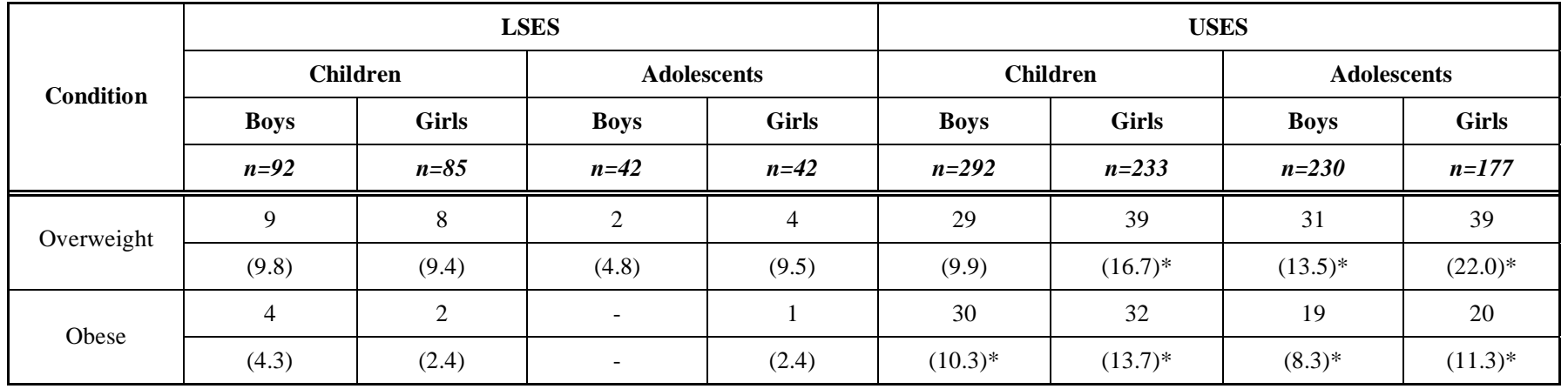

Data are shown in no (\%).

According to WHO 2007 BMI-for-Age percentile chart:

Cut off for Overweight; $\geq 85^{\text {th }}$ percentile.

Cut off for Obesity; $\geq 97^{\text {th }}$ percentile.

There were significant differences $(\mathrm{p}<0.05)$ seen in the prevalence of overweight and obesity between the two groups of socio economic status.

LSES - low socio economic status; HSES - high socio economic status.

*Denotes statistical significance $\mathrm{P}<0.05$. 
Table 2. Mean and SD Values of Anthropometric Measurements of School Children from Lower and Upper Socioeconomic Status

\begin{tabular}{|c|c|c|c|c|c|c|c|c|c|c|c|c|}
\hline \multirow{5}{*}{ Measures } & \multicolumn{6}{|c|}{ Children } & \multicolumn{6}{|c|}{ Adolescents } \\
\hline & \multicolumn{6}{|c|}{ (Age 8-12 years) } & \multicolumn{6}{|c|}{ (Age 13-15 years) } \\
\hline & \multicolumn{2}{|c|}{ Boys } & \multirow{3}{*}{$\begin{array}{c}\mathbf{P} \\
\text { value }\end{array}$} & \multicolumn{2}{|c|}{ Girls } & \multirow{3}{*}{$\begin{array}{c}\mathbf{P} \\
\text { value }\end{array}$} & \multicolumn{2}{|c|}{ Boys } & \multirow{3}{*}{$\begin{array}{c}P \\
\text { value }\end{array}$} & \multicolumn{2}{|c|}{ Girls } & \multirow{3}{*}{$\begin{array}{c}\mathbf{P} \\
\text { value }\end{array}$} \\
\hline & LSES & USES & & LSES & USES & & LSES & USES & & LSES & USES & \\
\hline & $n=92$ & $n=292$ & & $n=85$ & $n=233$ & & $n=42$ & $n=230$ & & $n=42$ & $n=177$ & \\
\hline $\begin{array}{c}\text { Weight } \\
(\mathrm{Kg})\end{array}$ & $\begin{array}{l}31.8 \\
\pm 8.0\end{array}$ & $\begin{array}{l}35.5 \\
\pm 9.9\end{array}$ & $<0.0001$ & $\begin{array}{r}32.3 \\
\pm 9.2\end{array}$ & $\begin{array}{c}41.5 \\
\pm 11.7\end{array}$ & $<0.0001$ & $\begin{array}{c}45.1 \\
\pm 11.0\end{array}$ & $\begin{array}{c}48.7 \\
\pm 12.9\end{array}$ & 0.090 & $\begin{array}{r}43.6 \\
\pm 10.7\end{array}$ & $\begin{array}{c}54.5 \\
\pm 12.8\end{array}$ & $<0.0001$ \\
\hline $\begin{array}{c}\text { BMI } \\
(\mathrm{Kg} / \mathrm{m} 2)\end{array}$ & $\begin{array}{l}16.2 \\
\pm 2.7\end{array}$ & $\begin{array}{l}16.9 \\
\pm 3.4\end{array}$ & $<0.071$ & $\begin{array}{l}16.2 \\
\pm 2.9\end{array}$ & $\begin{array}{l}18.5 \\
\pm 3.9\end{array}$ & $<0.0001$ & $\begin{array}{l}17.9 \\
\pm 2.7\end{array}$ & $\begin{array}{l}19.0 \\
\pm 3.7\end{array}$ & 0.066 & $\begin{array}{l}18.8 \\
\pm 3.1\end{array}$ & $\begin{array}{l}21.3 \\
\pm 4.4\end{array}$ & $<0.0001$ \\
\hline
\end{tabular}

LSES - Low socio economic status; USES - Upper socio economic status;

BMI - Body Mass Index; WC- Waist Circumference.

$\mathrm{P}<0.05$ denotes statistical significance.

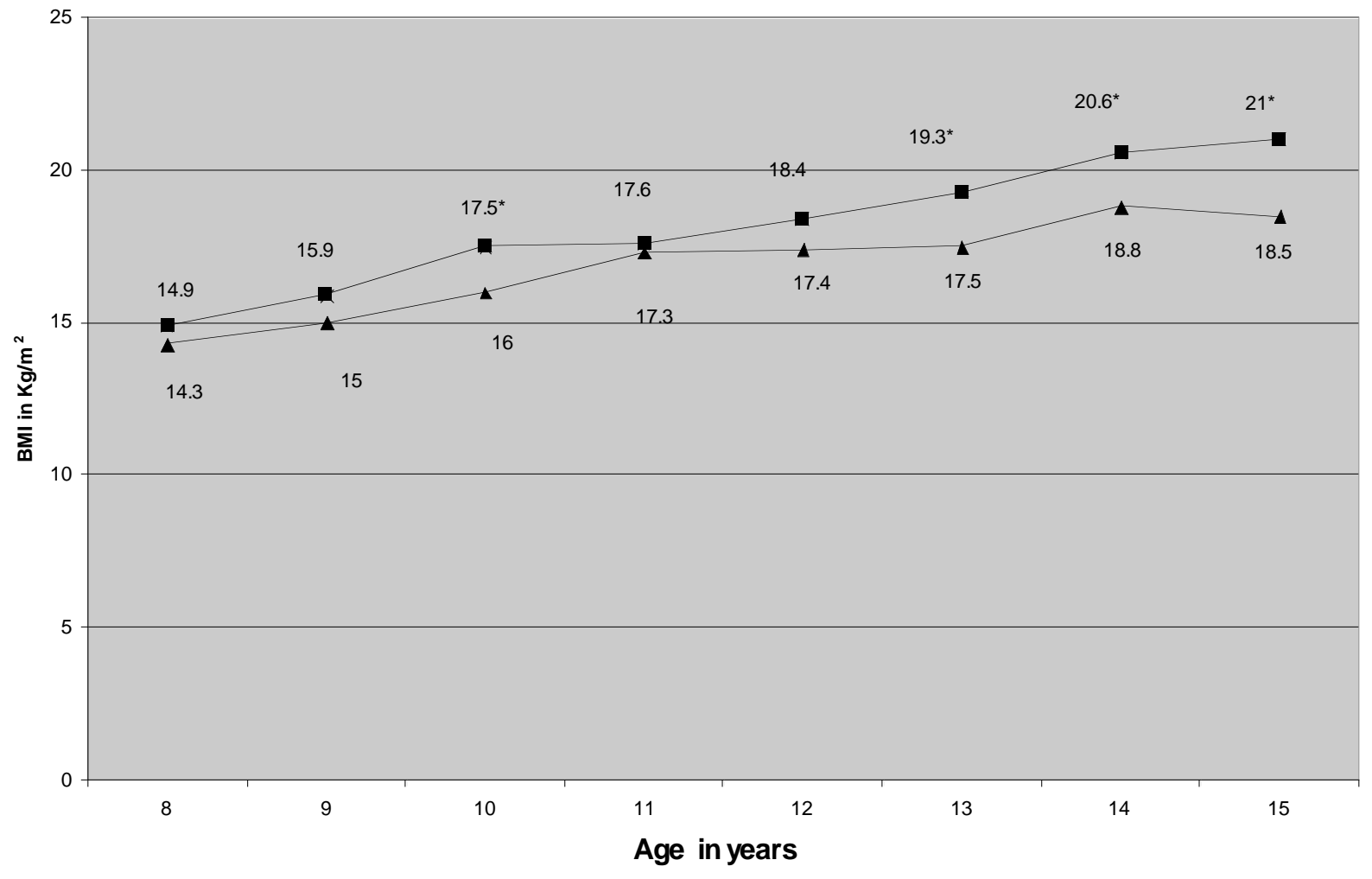

\section{-LSES - - USES}

Fig. (1). Distribution of mean BMI values according to age.

* Denotes statistical significance $\mathrm{P}<0.05$.

Age wise presentation of the mean values of body mass index (BMI) in $\mathrm{Kg} / \mathrm{m}^{2}$ for schoolchildren from upper socioeconomic status (USES) and low socioeconomic status (LSES).

Table 3. Higher scores were obtained by children aged 13 years and older, female gender and children from USES $(\mathrm{p}<0.0001) .50^{\text {th }}$ percentile for LSES fell on score 3 whereas it was on score 5 for USES.

\section{DISCUSSION}

An important finding of this study is an ever burgeoning prevalence of overweight among the urban school children 


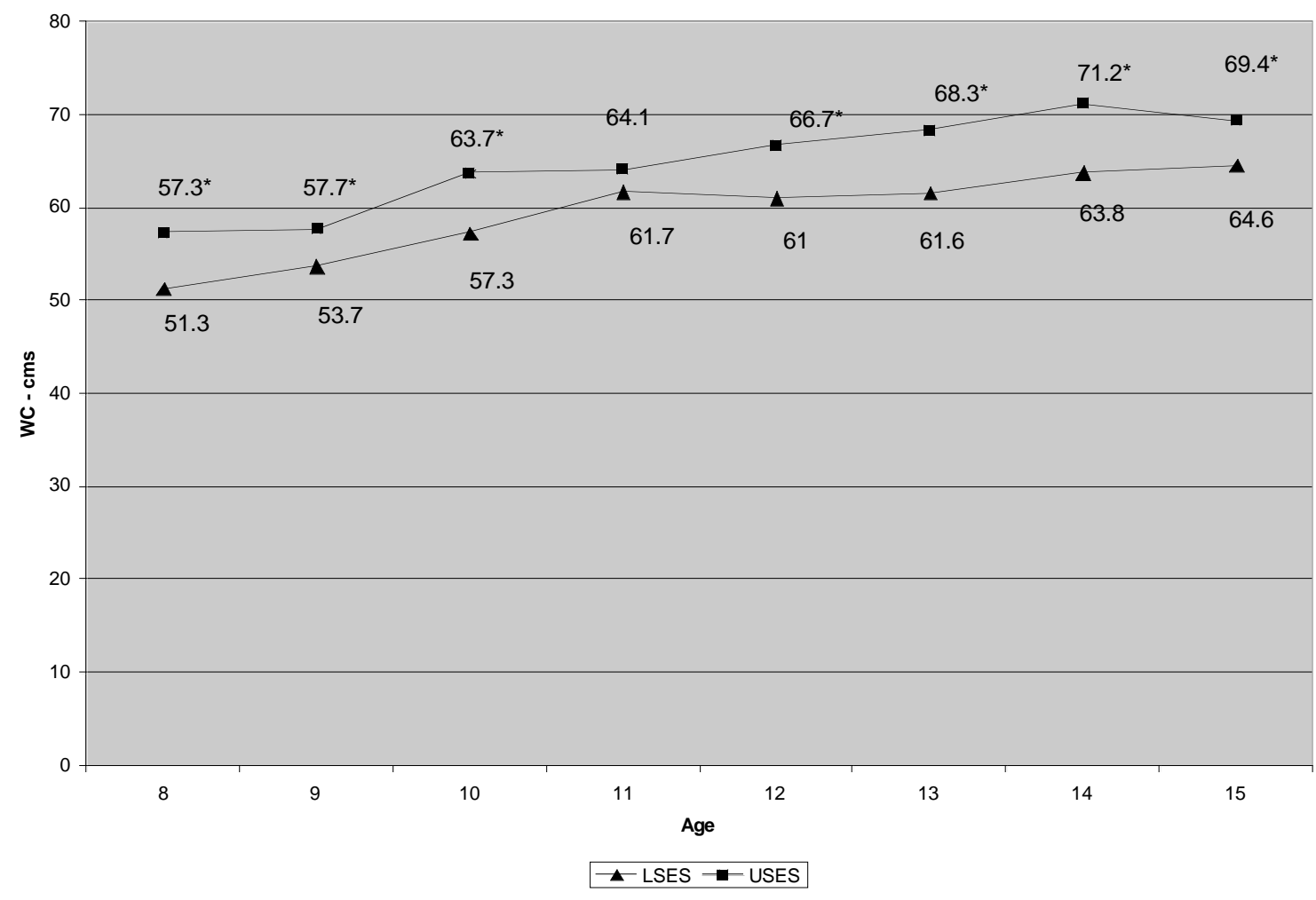

Fig. (2). Distribution of mean values of waist circumference according to age.

* Denotes statistical significance $\mathrm{P}<0.05$.

Age wise presentation of the mean values of waist circumference (WC) in centimeters $(\mathrm{cm})$ for schoolchildren from upper socioeconomic status (USES) and low socioeconomic status (LSES).

Table 3. Mean Values of Knowledge Scores According to Age, Gender and Socioeconomic Status

\begin{tabular}{|c|c|c|c|c|c|}
\hline & Variables $n=1193$ & Total n (\%) & Mean Score & SD & P Value \\
\hline Age in Years & $13-15$ & 491(41.3) & 5.2 & 1.8 & $<0.0001$ \\
\hline \multirow{2}{*}{ Gender } & Male & $656(55.0)$ & 3.9 & 1.8 & \multirow{2}{*}{$<0.0001$} \\
\hline & Female & $537(45.0)$ & 4.8 & 2.2 & \\
\hline
\end{tabular}

SD - Standard Deviation.

$\mathrm{P}<0.05$ Denotes statistical significance.

when compared to previous surveys in India [10, 11]. Subramanyam, et al. [11] showed the prevalence of overweight and obesity among affluent girls aged 10 - 15 years in Chennai was $9.6 \%$ and $6.2 \%$ respectively in 1998. Our study has shown higher figures which is suggestive of the obesity epidemic in $21^{\text {st }}$ century.

Another finding of this study is the socioeconomic influence in the prevalence of overweight and obesity. Prevalence of overweight and obesity was significantly higher among the USES. The mean values of BMI and waist circumference when compared with standard WHO 2007 reference charts, fell below the $50^{\text {th }}$ percentile for subjects from LSES while for USES, they were between $50^{\text {th }}$ and $85^{\text {th }}$ percentile. Hence we infer that overweight and obesity is more in USES. These results show consistency with results from other Indian studies [12]. Female gender had higher preponderance to overweight and was more prominent in USES. However puberty and growth spurt which occur at an earlier age for girls may account to confounding effect. It has been reported that the number of adipose tissue cells increase during these periods followed by slowdown after puberty [13]. Reports from other studies showed that the prevalences are marginally lesser during post pubertal period [14]. Results from studies done in India and other parts of the 
globe also showed that female gender are at risk of being overweight and obese [15-17].

The study showed widespread prevalence of unhealthy lifestyle habits. Percentage of children scoring minimum of 0 and maximum of 8 among the LSES were $5.2 \%$ and $2.4 \%$ respectively while it was $0.5 \%$ and $7.6 \%$ for USES children. Rapid epidemiological transition is currently sweeping across India, which has a direct impact on food habits and lifestyle. Springing up of fast-food outlets and easy availability of junk food is a matter of concern. Today's children prefer these foods to fruits and vegetables [18-21]. In our study, we found that the children from private schools consumed more of fast food items and carbonated drinks as all these food items were easily available in their school canteen. Further research is required to collect complete data on quality and quantity of food consumption, eating behavior and to determine its association with knowledge which was beyond the scope of this study.

Though the children were well informed about the good effects of physical activity, we found that they were not engaged in daily physical activity. Only $30 \%$ of the overweight and obese children were engaged in atleast 60 minutes of daily physical activity, which is suggestive of the sedentary lifestyle of the younger generation. The recent trend is that the school children concentrate more on academics and are involved in less of sports and activities. Leisure hours are spent in watching TV or playing computer/ video games, thus explaining the sedentary lifestyle of today's school children. These findings were consistent with other studies [15, 20, 22, 23].

The two factors- USES and TV watching showed significant association with overweight and obesity in this study. Unlike other studies, although levels of physical activity did not come out as a risk factor in the regression analysis, it showed independent association using chi-square test. Normal values of BMI were distributed in the higher tertiles of physical activity [22,23].

Nevertheless obesity is a result of complex interaction between genetic and environmental factors [24, 25]. Further research is recommended to explore the link between geneenvironment-obesity relations among children. Moreover since the WHO 2007 charts were derived from heterogeneous data sets across 22 countries, a lot of research is needed to establish its accuracy and correlate with external environmental factors.

To summarize, our results suggest that childhood obesity is on the rise especially among the urban affluent children and the knowledge about lifestyle related diseases like obesity and diabetes and their prevention is very poor. Moreover the persistence of unhealthy practices among the children must be given attention. The health impact of increasing prevalence of overweight and obesity among children and adolescents is a matter of serious concern. Heart disease and diabetes were rare among children and young adults in the previous century. But today, supposed to be the diseases of the elderly, these diseases are frequently occurring in the younger generation. This study has thus highlighted the need to not only improve the awareness on prevention of childhood obesity among children but a need to motivate and reinforce them to practice healthy lifestyle is utmost essential.

\section{RECOMMENDATION}

These findings suggest a need for planning school based intervention programs for preventing childhood obesity and increasing the level of awareness on the ill effects of obesity, among parents, teachers and children in order to control the escalating prevalence. Certain guidelines and policies like school canteen policy, healthy food practices, inclusion of health related topics in curriculum and compulsory physical training classes must be introduced in the schools. There must be a multi sector approach from the government, school authorities and parents to introduce policies and guidelines to curb on the obesity menace and to help today's children to live a long healthy life tomorrow.

\section{CONFLICT OF INTEREST}

Conflict of Interest is none.

\section{ACKNOWLEDGEMENTS}

We thank the school Principals for granting permission to conduct the study. We thank the children who participated in the study and extended their full co-operation. We are thankful to our epidemiology team members for collection of data and data handling. This study was funded by Diabetes Research centre.

\section{REFERENCES}

[1] Gupta R, Goyle A, Kashyap S, Agarwal M, Consul R, Jain BK. Prevalence of atherosclerosis risk factors in adolescent school children. Indian Heart J 1998; 50(5): 511-5.

[2] Stein AD, Thompson AM, Waters A. Childhood growth and chronic disease: evidence from countries undergoing the nutrition transition. Matern Child Nutr 2005; 1(3): 177-84.

[3] Rao S, Kanade A, Kelkar R. Blood pressure among overweight adolescents from urban school children in Pune, India. Eur J Clin Nutr 2007; 61(5): 633-41.

[4] Kelishadi R. Childhood overweight, obesity, and the metabolic syndrome in developing countries. Epidemiol Rev 2007; 29: 62-76.

[5] Mohan V, Jaydip R, Deepa R. Type 2 diabetes in Asian Indian youth. Pediatr Diabetes 2007; (8 Suppl 9): 28-34.

[6] Bhargava SK, Sachdev HS, Fall CH, et al. Relation of serial changes in childhood body-mass index to impaired glucose tolerance in young adulthood. N Engl J Med 2004; 350(9): 865-75.

[7] Chatterjee P. India sees parallel rise in malnutrition and obesity. Lancet 2002; 1948: 360(9349).

[8] Ke-You G, Da-Wei F. The magnitude and trends of under- and over-nutrition in Asian countries. Biomed Environ Sci 2001; 14 (1-2): 53-60.

[9] Bulletin of the World Health Organization. September 2007; 85 (9): 660-7.

[10] Sharma A, Sharma K, Mathur KP. Growth pattern and prevalence of obesity in affluent school children of Delhi. Public Health Nutr 2007; $10(5):$ 485-9.

[11] Subramanyam V, Jayshree R, Rafi M. Prevalence of overweight and obesity in affluent adolescent girls in Chennai in 1981 and 1998. Indian Pediatr 2003; 40: 332-6.

[12] Marwaha RK, Tandon N, Singh Y, et al. A study of growth parameters and prevalence of overweight and obesity in school children from Delhi. Indian Pediatr 2006; 43(11): 943-52.

[13] Hirsch J. Fat cell number and size as a determinant of subsequent obesity: Childhood obesity. NewYork: John Wiley and Sons 1995.

[14] Laxmaiah A, Nagalla B, Vijayaraghavan K, Mohanan N. Factors affecting prevalence of overweight among 12 to 17 year old urban adolescents in Hyderabad, India. Obesity 2007; 15(6): 1384-90. 
[15] Anthony JG, Stewart BH, Joel G, et al. Overweight among children and adolescents in a native Canadian community: prevalence and associated factors. Am J Clin Nutr 2000; 71: 693-700.

[16] Mohammadpour AB, Rashidi A, Karandish M, Eshraghian MR, Kalantari N. Prevalence of overweight and obesity in adolescent Tehrani students, 2000-2001: an epidemic health problem. Public Health Nutr 2003; 7(5): 645-8.

[17] Sidhu S, Kaur N, Kaur R. Overweight and Obesity in affluent school children of Punjab. Ann Hum Biol 2006; 33(2): 255-9.

[18] Gillis LJ, Bar OO. Food away from home, sugar-sweetened drink consumption and juvenile obesity. Am Coll Nutr 2003; 22: 539-45.

[19] Neumark D, Story M, Hannan PJ, Stat M, Croll J. Overweight status and eating pattern among adolescent: where do youth stand in comparison with the healthy people 2010 objectives? Am J Public Health 2002; 92: 844-50.

[20] Merchant AT, Dehghan M, Cook DB, Anand SS. Diet, physical activity and adiposity in children in poor and rich neighborhoods:
A cross-sectional comparison. Nutr J 2007.http: //www.nutritionj. com/contents/6/1/1

[21] Amin TT, Al-Sultan AI, Ali A. Overweight and Obesity and their association with dietary habits, and sociodemographic among male primary school children in Al-Hassa, Kingdom of Saudi Arabia. Indian J Comp Med 2008; 33(3): 172-81.

[22] Francisco BO, Jonatan RR, Michael S. Physical activity, overweight and central adiposity in Swedish children and adolescents: the European youth heart study. Int J Behav Nutr Phys Act 2007; 4: 61

[23] Pateric K, Calfas GJ, Zabinski MF, Cella J. Diet, Physical activity and secondary behaviours as risk factors for overweight in adolescence. Arch Pediatr Adolesc 2004; 158: 385-90.

[24] Sydney EE,Walts B, Perusse L, et al. The human obesity gene map: the 2003 update. Obes Res 2004; 12: 369-439.

[25] Nobel EP, Blum K, Ritchie T, Montgomery A, Sheridan PJ. Allelic association of the D2 dopamine receptor gene and obesity. Int J Eat Disord 1994; 15: 205-17.

Received: September 23, 2008

Revised: December 04, 2008

Accepted: December 16, 2008

(c) Tharkar and Viswanathan; Licensee Bentham Open.

This is an open access article licensed under the terms of the Creative Commons Attribution Non-Commercial License (http: //creativecommons.org/licenses/bync/3.0/), which permits unrestricted, non-commercial use, distribution and reproduction in any medium, provided the work is properly cited. 